[Aus dem Institut für Infectionskrankheiten zu Berlin.]

\title{
Ueber die Züchtung der Typhusbacillen aus Roseolaflecken nebst Bemerkungen über die Technik bakteriologischer Blutuntersuchungen.
}

Von

Dr. F. Neufeld,

Assistenten am Institut.

Kurze Zeit, nachdem zum ersten Male Typhusbacillen aus dem Stuhle eines Kranken isolirt waren, begannen die Versuche, auch die Roseolaflecken der Typhuspatienten zur bakteriologischen Diagnose zu verwerthen. In der Mehrzahl der Fälle wurde gleichzeitig mit dem Roseolablute das aus einer Vene oder auch aus der Fingerkuppe durch Stich entnommene Blut anf die Anwesenheit von Typhusbakterien untersucht. Ueber eine grössere Anzahl von positiven Ergebnissen berichten zwei Autoren: Neuhauss ${ }^{1}$ und Thiemich. ${ }^{2}$

Neuhauss gelang es bei seinen schon im Jahre 1886 im Krankenhause Friedrichshain gemachten Untersuchungen, bei 9 unter 15 Patienten Typhusbacillen aus den Poseolaflecken zu züchten. Das Blut wurde auf sehräg erstarrter Gelatine ausgestrichen, und zwar wurden von jedem Patienten 4 soleher Gelatineröhrchen angelegt, desgleichen je 4 mit Blutstropfen aus Hautschnitten am Arm. Letztere blieben sämmtlich steril, auch in allen übrigen Röhrchen fanden sich niemals Verunreinigungen.

Thiemich hatte unter 7 Fällen in der Breslauer Universitätsklinik 3 positive Befunde. Er vermischte das Roseolenblut mit flüssig gemachtem Agar, meist schon am Krankenbett, und goss Platten davon. Die Zahl der aufgegangenen Typhuscolonieen war stets eine ganz geringe, oft waren daneben Staphylokokken als Verunreinigung gewachsen.

Ausser den Berichten der genannten beiden Autoren finden sich nur noch ganz vereinzelte Angaben über positive Befunde; ihnen gegenüber

1 Berliner klin. Wochenschrift. 1886. Nr. 6 u. 24.

${ }^{2}$ Deutsche med. Wochenschrift. 1895. Nr. 34. 
steht eine weit überwiegende Mehrzahl von Fällen, in welchen eine Reihe von Autoren mit denselben Untersuchungsmethoden durchaus negative Resultate erzielt hatten, ${ }^{1}$ so Gaffky, Fränkel und Simmonds, Widal und Chantemesse, Curschmann, Wiltschur, Merkel und Goldschmidt, Seitz. Der letztere Autor untersuchte speciell in Nachprüfung der Resultate von $\mathrm{N}$ e uha uss nach derselben Methode, wie dieser, 14 Reseolen ohne ein einziges Mal Typhusbacillen zu cultiviren; dieselbe Methode wandte Janonski ${ }^{2}$ an 25 Patienten an, ebenfalls ohne einen einzigen positiven Befund. Nur Rütimeyer konnte nach Neuhauss aus einer von 13 untersuchten Roseolen eine Colonie erhalten, die er als Typhus identificirte. ${ }^{3}$

In Rücksicht auf diese überwiegende Zahl von negativen Ergebnissen und vor allem wohl, weil kein Erklärungsgrund für die Inconstanz der Befunde gegeben war, ist denn die bakteriologische Untersuchung der Roseolen; die Neuhauss vor so langer Zeit schon als ein verhältnissmässig einfaches, anch dem praktischen Arzt zugängliches Hülfsmittel der Typhusdiagnose empfohlen hatte, selbst in Kliniken und Laboratorien niemals in Aufnahme gekommen und eine weitere Ausbildung ihrer Methodik nicht versucht worden, während inzwischen für die Typhusdiagnose aus den Fäces eine grosse Reihe von Verbesserungen oder wenigstens Veränderungen der alten Methoden angegeben wurde, und während die Widal'sche Methode der Typhusdiagnose, welche doch ziemlich hohe Anforderungen an die Uebung des Untersuchers stellt, in kürzester Zeit sich in allen Krankenhäusern einbürgerte. Bei der grossen Zahl der negativen Befunde aus den Roseolen und bei den Schwierigkeiten, die zumal früher die Identification des Typhuserregers machte, mögen auch wohl viele bezweifelt haben, ob jene Autoren in allen Fällen echte Typhusbacillen vor sich gehabt haben.

Im Herbst 1896 erhielt ich nun von Hrn. Geheimrath Koch den Auftrag, diese Versuche wieder aufzunehmen, um zu sehen, ob die bakteriologische Untersuchung roseolaverdächtiger Flecken neben der Untersuchung der Fäces und neben der damals eben von Widal veröffentlichten Methode ihre Berechtigung habe, und was sie etwa, gewissermassen in Concurrenz mit diesen beiden Methoden, für die bakteriologische Diagnose

\footnotetext{
1 Centralblatt für Bateteriologie. Bd. V. S. 657.

Siehe die Litteraturangaben bei Thiemich, a. a. O. und Curschmann, Der Unterleibstyphus. S. $161 \mathrm{ff}$.

${ }^{3}$ Nach Abschlass dieser Arbeit fand ich bei Singer, Ueber Varietäten des Typhusexanthems und ihre Bedeutung (Wiener klin. Wochenschrift. 1896) einen positiven Befund aus Roseolen, sowie vier positive ans einem atypischen als ,folliculäre Infiltrate" beschriebenen Typhusexanthem ohne Angabe der angewandten Methode.
} 
des Typhus zu leisten vermöge. Natürlich ist der praktische Werth dieser Versuche von vornherein dadurch beschränkt, dass sie nur in einer gewissen Zahl von Typhusfällen möglich sind und dass die zum Theil gerade zweifelhaftesten Fälle, in denen ein Roseolaexanthem fehlt, davon ausgeschlossen sind; wenn man jedoch diese Beschränkang berücksichtigt, so hat, wie die nachfolgende Zusammenstellung zeigen wird, das Verfahren der Roseolenuntersuchung die Concurrenz mit den anderen bakteriologisehen Methoden unerwartet gut bestanden; wo es anwendbar war, erwies es sich als weit einfacher und schneller zum Ziel führend, als die Untersuchung der Fäces, und hatte auch der Widal'schen Reaction gegenüber den Vortheil, dass es in fast allen Fällen früher ein positives Resultat ergab, als diese. Nicht gelungen ist mir die Zũchtung des Typhusbacillus aus Roseolaflecken nur in einem Falle (unter 10), dem letzten der angeführten, in welchem jedoch nur 3 rerdächtige Flecke auftraten; in diesem Falle liessen auch die anderen bakteriologisehen Methoden während der ganzen Krankheitsdauer völlig im Stich: trotz mehrfacher Untersuchung wurden Typhusbacillen im Stuhl vermisst und die sehr oft wiederholte Widal'sche Probe ergab stets ein negatives Resultat; erst nachträglich brachte der Nachweis der Pfeiffer'schen Antikörper im Serum der Reconvalescentin die bakteriologische Bestätigung der Diagnose. Von den übrigen 9 Fällen bedurfte es nur in einem einer wiederholten Untersuchung, um die Bacillen aus den Roseolen zu züchten, in allen anderen wuchsen bereits bei der ersten Untersuchung in einem oder in mehreren Röhrchen Typhusbacillen; dabei wurden in der Regel jedesmal 3 bis 5 der verdächtigen Hautflecke angeschnitten.

Dieses verhältnissmässig gute Resultat bei meinen Roseolenuntersuchungen verdanke ich der $A \mathrm{n} w e n d u n g$ flüssiger Nährböden. Von vornherein hielt ich es nämlich für wahrscheinlich, dass, wenn in der That die Roseolaflecke als Metastasen der typhösen Darmerkrankung anzusehen sein sollten, die Typhusbacillen hier nur einen vorübergehenden Schlupfwinkel gefunden hätten, wo sie aus irgend welchen Gründen den baktericiden Kräften des Blutes für einige Zeit entzogen sind, dass jedoch eine Vermehrung nur in sehr beschränktem Haasse zu Stande kommt; wegen ihrer geringen Anzahl könnten sie dann der baktericiden Wirkung des Blutes, der sie durch die zur Entnahme nothwendige Incision ausgesetzt werden, in sehr viel kürzerer Zeit erliegen als die bisherigen Experimente über die baktericide Kraft des Serums vermuthen lassen. Ich suchte deshalb die aus dem Einschnitt hervorquellenden Blutstropfen möglichst rasch in flüssigem Nährboden zu verdünnen. Begreiflicher Weise findot diese Verdünnung des Blutes in Bouillon schneller und ausgiebiger statt, als in dem von Thiemich verwandten, flüssig gemachten Agar. 
Doch sehe ich den hauptsächlichsten Grund, weshalb ich bei meinen Untersuchungen bessere Resultate als Thiemich erzielte, nicht in dem Ersatz des flüssigen Agars durch Bouillon, sondern in der richtigeren Erkenntniss des Grundes der Misserfolge. In der That zeigte es sich bei den ersten Versuchen, dass die Typhusbacillen nur in Bouillonröhrehen, nicht aber auf den Agar-Ausstrichen gewachsen waren; 2 Mal jedoch waren sie im Condenswasser des Agarröhrchens gewachsen und auch auf die Agaroberfläche soweit übergegangen, als diese augenscheinlich vom Condenswasser bespült worden war. Seit dieser Erfahrung impfte ich die Agarröhrchen stets in das Condenswasser, zu dem ich oft noch einige Cubikcentimeter Bouillon zufüllte, und bespülte hiermit durch Neigen des Röhrehens die Agarfläche.

Die Anlegung der Culturen gestaltet sich dann folgendermassen: Zunächst wird die betreffende Hautstelle ohne starkes Drücken und Reiben mit einem im Alkohol und Aether getauchten Wattebausch gereinigt, alsdann mit einem spitzen Scalpell oder einer Impflancette ein seichter Finschnitt in die Roseole gemacht; nun kratzt man, bevor noch der erste Blutstropfen hervordringt, mit der Spitze desselben Messers etwas Gewebssaft aus der kleinen Wunde heraus und bringt diesen sofort in Bouillon; aus dem Röhrehen bringt man mit der Messerspitze einige Tropfen Bouillou auf die Wunde, um die hervorquellenden Blutstropfen sogleich zu verdünnen; dieselben werden dann ebenfalls in Bouillon oder in das Condenswasser von Agarröhrchen, wie oben besehrieben, verimpft. Gewöhnlich habe ich von jeder Roseole auf diese Weise 1 Agar- und 1 bis 2 Bouillonröhrchen geimpft. Stets empfielt es sich, mehrere Flecke gleichzeitig in Untersuchung zu nehmen, da es auch mit der angegebenen Methode nicht gelingt, aus jedem derselben den Typhusbacillus zu züchten, sei es, dass in der geringen Menge der aus einem solchen Schnitt herausgekratzten oder durch das hervorquellende Blut herausgesqülten Gewebsflüssigkeit gerade keine Bacillen enthalten waren, oder dass sie trotz aller Schnelligkeit des Vorgehens bei der Mischung mit dem Blut zu Grunde gingen, sei es, dass die Röthung der Flecke noch eine Zeit lang bestehen bleiben kann, nachdem die Typhusbacillen darin bereits zu Grunde gegangen sind. Hierfür spricht, dass ich öfters bei solchen Roseolaflecken, die schon einige Tage bestanden und bereits im Abblassen begriffen sehienen, negative Resultate hatte, dagegen die meisten positiven aus ganz zarten, erst kürzlich aufgetretenen. Schliesslich ist es schon aus dem Grunde geboten, stets mehrere der verdächtigen Flecke zu untersuchen, weil es bekanntlich unmöglich ist, eine Typhusroseole mit aller Sicherheit als solche zu erkennen und von jeder anderen Hautefflorescenz zu unterscheiden. Besonders dubiös sind derartige Exantheme, wenn dabei überhaupt nur ganz spärliche roseolenähnliche Flecke, etwa nur 2 oder 3 auftreten. Wenn ich daher 
durchaus die Vollständigkeit meiner kleinen Statistik retten wollte und die Zahl meiner positiven Erfolge von 90 auf 100 Procent erhöhen, so könnte ich den letzten Fall der nachfolgenden Zusammenstellung ausscheiden, indem ich dahin gestellt sein lasse, ob die 3 Hautflecke, die im Verlauf der Erkrankung auftraten, und von denen 2 untersucht wurden, ein wirkliches Roseolaexanthem gewesen sind. Ich bin jedoch überzeugt, dass auch bei Anwendung von Bouillonculturen und bei aller Schnelligkeit des Vorgehens Fehlerfolge durchaus erklärlich sind.

Meine Voraussetzung, dass die geringe Anzahl der in einer Roseola vorhandenen Bacillen bereits in der kurzen Zeit, in welcher das aus der Incisionswunde einer solchen Roseola hervorquellende Blut mit dem bacillenhaltigen Gewebssaft sich mischt, also in der Zeit von einer oder wenigen Minuten, vielleicht auch schon in Bruchtheilen einer Minute durch die baktericide Kraft des Blutes abgetödtet werden können, ist, wie ich glaube, dadurch hinreichend bestätigt worden, dass die Züchtung nur bei möglichst raschem Vorgehen und schneller, ausgiebiger Verdünnung des gewonnenen Blutes gelang.

Trotzdem lag es nahe, nach einer directen, experimentellen Bestätigung hierfür zu suchen. Die bisherigen Untersuchungen über die baktericide Wirkung des Blutserums können bei den dabei angewandten Methoden einen solchen directen Beweis nicht liefern, da sie sich im Allgemeinen auf die Abtödtung grösserer Bakterienmengen in längerer Zeit beziehen. So sagen Behring und Nissen bei der Beschreibung der von ihnen, wie vorher von Nutall gebrauchten Versuchsanordnung: „Dabei wird von der Voraussetzung ausgegangen, dass das ganz kurz dauernde Zusammensein der Bakterien mit dem Serum ( 1 bis 2 Minuten) eine Abtödtung lebender Keime nicht zur Folge hat."

Thiemich hat in seiner schon citirten Arbeit über Roseoleu die Möglichkeit gestreift, dass bereits während der kurzen Dauer der Untersuchung eine Abtödtung von Typhuskeimen stattinden könne und sucht sich experimentell hierüber Aufklärung za verschaffen. Er brachte eine Oese Typhusaufschwemmung von bekanntem Bakteriengehalt in 1.0 bis $2 \cdot 0^{\mathrm{cm}}$ Blut und goss hiervon nach Verlauf von 20,40,60 u. s. w. Secunden Agarplatten aus. „Dabei stellte sich heraus, dass innerhalb der ersten 2 bis 3 Minuten keine deutliche Abtödtung der Typhusbacillen eintrat." Hieraus schliesst der Autor, dass bei seiner Versuchsanordnung bei der Roseolenuntersuchung diese Fehlerquelle, die Abtödtung nämlich durch das Blut während der Entnahme, ausgeschlossen sei.

Ich habe nun eine Anzahl von Versuchen in der Weise angestellt, dass ich eine ganz kleine Anzahl von Typhuskeimen in Reagensröhrchen

' Diese Zeitschrift. Bd. VIII. S. 413. 
zu einigen Tropfen Serum - meist $0.2^{\mathrm{ecm}}$ - zusetzte, und nachdem das Serum eine gewisse Zeit auf die Bacillen eingewirkt hatte, rasch einige Cubikcentimeter Bouillon zufüllte. Natürlich konnte ich so nur feststellen, $o b$ sämmtliche eingebrachten Keime nach Verlauf einer gewissen kurzen Zeit abgetödtet waren.

In einer ganzen Anzahl derartiger Versuche erhielt ioh in der That ein gleichmässiges, positives Resultat, wobei verschiedene Sera sich verschieden wirksam erwiesen; die vollständige Abtödtung erfolgt innerhalb weniger Minuten, bisweilen auch in Bruchtheilen einer Mlinute. Es gelang mir jedoch nicht, immer so gleỉchmässige Resultate zu erlangen, wie ich aunehme, deshalb, weil sich gar zu leicht einzelne Keime, etwa an der Wandung des Reagensröhrchens, der schnellen Einwirkung des Serums entziehen. In entsprechender Weise beobachtete $\mathrm{Nu}$ tall bei seinen Versuchen, dass auffallend häufig, wenn Hunderte von Keimen durch das Serum abgetödtet waren, auf den Gelatineplatten noch einige wenige Colonieen aufgingen. ${ }^{1}$

Was die Identificirung der aus den Roseolen gewonnenen Culturen anlangt, so habe ich in allen Fällen (mit Ansnahme des Falles 5, der ausserhalb des Instituts zur Beobachtung kam) die Immunitätsreaction nach $P$ feiffer angestellt, ferner wurde jedesmal das Wachsthum auf Petrus chky's Lackmusmolke, sowie die Agglutinationswirkung eines stark verdünnten, hochwerthigen Typhusserums auf die betreffende Cultur untersucht, in den ersten Fällen ausserdem auch die übrigen bekannten Typhusproben gemacht. Im Laufe dieser Untersuchungen habe ich mich jedoch überzeugt, dass eine Verwechselung mit typhusähnlichen Bakterien hierbei kaum zu befürchten ist. Wie aus den unten zu erwähnenden Protocollen sich ergiebt, waren die häufig vorkommenden und wohl unvermeidlichen Verunreinigungen meist durch Staphylokokken bedingt, nur einmal fand sich ein gut beweglicher Bacillus, dessen Colonien auf Agar Aehnlichkeit mit Typhuscolonieen hatten; er unterschied sich jedoch sofort durch vollständiges Ausbleiben von Agglutination, sowie durch sein Wachsthum auf Lackmusmolke vom Typhusbacillus und ist daher nicht weiter untersucht worden. Ich glaube daher, dass man niemals irren wird, wenn man eine aus einer Roseole erhaltene typhusähnliche Cultur nur mit einem etwa auf $1: 50$ verdünnten hoehwirksamen Typhusserum prüft; bei dieser Prüfung stört eine etwaige Verunreinigung des Typhus haltigen Bouillonröhrchens durch Staphylokokken durchaus nicht; man kann also der direct aus der Roseole angelegten Bouilloncultur das agglutinirende Serum zusetzen und so in weniger als 24 Stunden ein sicheres Resultat haben. Natürlich kann man nach 24 Stunden auch bereits Agarculturen haben, wenn man von den am Tage angelegten Bonillonculturen etwa Abends

\footnotetext{
1 Diese Zeitschrift. Bd. IV. S. 387-398.
} 
noch Agar-Ausstriche macht. Doch ist hierbei zu beachten, wie aus dem Fall 3 hervorgeht, dass das Wachsthum der Bouillonculturen durch den hemmenden Einfluss des beigemengten Blutes verzögert sein kann.

Noch auf eine andere hemmende Einwirkung des zugefügten Blutes muss man gefasst sein, dass nämlich die Typhusbacillen in der Bouilloncultur unbeweglich oder in Häufchen angeordnet erscheinen; impft man aus dem ersten Röhrchen auf Agar oder auch auf ein neues Röhrchen derselben Bouillon über, so erhält man eine vollbewegliche Cultur.

Die Virulenz der aus den Roseolen gewonnenen Culturen scheint ungefähr in denselben Grenzen zu schwanken, wie es bei den aus den Fäces stammenden der Fall ist. Die virulenteste derselben tödtete Meerschweinchen ron etwas über $300 \mathrm{grm}$ in der Dosis $1 / 20$ Oese in 24 Stunden. In dem Falle Braun hatte Hr. Dr. Uhlenhuth gleichzeitig eine Cultur aus den Fäces erhalten, bei einer vergleichenden Virulenzprüfung zeigten sich beide Culturen annähernd gleich virulent.

Wie oben ausgeführt, bin ich von der Annahme ausgegangen, dass die Anzahl der in einer einzelnen Roseole enthaltenen Typhuskeime eine sehr geringe ist. Es hat sich mir diese Voraussetzung dadurch bestätigt, dass in der Regel bei Agarröhrchen, die, wie beschrieben, in das Condenswasser geimpft waren, die Typhusbacillen nur im Condenswasser zar Entwickelung kamen, nicht aber in der ausgiebig damit bespülten Agaroberfläche.

Unter diesen Umständen ist natürlich keine Aussicht vorhanden, etwa in Schnitten durch eingebettete excidirte Roseolaflecken die Bacillen nachweisen zu können; ich habe, zumal bereits eine Anzahl negativer Resultate auf diesem Gebiete vorliegen ${ }^{2}$, nur einmal eine Roseole excidirt und eine grössere Reihe von Schnitten gefärbt - ohne verdächtige Bacillen darin zu sehen.

Ueber die Bakterien, welche sich als Verunreinigungen in den Culturröhrchen einstellten, finden sich die Angaben in dem nachstehenden Berichte. Ich möchte hervorheben, dass ich darunter niemals die Entwickelung von Streptokokken oder eines Bacterium coli beobachtet habe; die Gefahr, diese beiden Bakterienarten als Verunreinigungen aus einer mit Alkohol und Aether gereinigten Hautfläche zu erhalten, ist also wohl nicht gross. Von Staphylokokken dagegen erhält man, wie bekannt, bisweilen eine grosse Anzahl von-Keimen auf einmal, offenbar, wenn gerade ein Drüsenausführungsgang getroffen ist.

In der Zusammenstellung aller von mir untersuchten Fälle, die ich nunmehr folgen lasse, habe ich nur kurze Angaben aus den Krankengeschichten entnommen, die erkennen lassen, zu welchem Zeitpunkte die Diagnose bakteriologisch erwiesen wurde, und inwieweit die klinischen Be-

${ }^{1}$ Ernst, Ziegler's Beiträge. Bd. VIII. S. 195 Anmerkung. - Curschmann cit. nach Janowski, a. a. 0 . 
funde eine solche Sicherung noch als wünschenswerth erscheinen liessen Wenn auch natürlich zumal die Fälle mit reichlichem und charakteristischem Exanthem bereits klinisch die sichersten sind, so galt doch z. B. im Fall 3, wo, wie häufig, die Roseolaeruption durchaus nicht charakteristisch war, noch am selben Tage, wo bereits der Bacillenbefund vorlag, die Diagnose: Typhus aus den klinischen Symptomen als durchaus unwahrscheinlich.

-Ausfübrlich gebe ich dagegen in sämmtlichen Fällen die Beobachtungen über die Widal'sche Reaction wieder, gleichzeitig als Beitrag zur Kritik dieser Methode. Der Zeitpunkt des Eintrittes einer sich unzweideutig über die Norm erhebenden Agglntinationswirkung variirt aus unbekannten Ursachen sebr stark; es ist jedoch von Interesse, dass dieselbe während der ganzen Dauer eines unzweifelhaften Typhusfalles äberhaupt fehlen kann, wie der Fall 10 zeigt. Dabei ist in diesem Falle das Blut so oft untersucht worden, dass auch ein nur vorübergehendes Auftreten der Widal'schen Reaction uns nicht entgangen wäre; zum praktischen $Z$ weck der Diagnose wird natürlich Niemand eine sorgfältige Titrirung der Agglutinationswirkung des Blutes so häufig wiederholen wollen. Als positiv wurde die Widal'sche Reaktion angesehen, wenn das Serum in der Verdünnung $1: 30$, nachdem das Präparat einige Zeit (bis zu 30 Minuten) bei Zimmertemperatur gelegen hatte, eine gut bewegliche Typhuscultur vollstândig agglutinirte. Meist übrigens erfolgte in ganz kurzer Zeit noch ein erheblicher Anstieg in der Agglutinationswirkung. Von den folgenden 10 Fällen wurde in 9 die Widal'sche Probe angestellt: in einem ermöglichte sie am 5. Krankbeitstage eine sichere Frühdiagnose, $1 \mathrm{Mal}$ trat sie in der zweiten, $6 \mathrm{Mal}$ in der dritten und vierten Woche auf, während sie $1 \mathrm{Mal}$, wie hervorgehoben, vollständig ausblieb.

Das Material meiner Untersuchungen bestand aus Patienten der unter Leitung des Hrn. Prof. Brieger stehenden Krankenabtheilung des Instituts mit Ausnahme des Falles 5; für die Ueberlassung des letzteren bin ich Hrn. Sanitätsrath Frey muth, dem Oberarzt des Danziger Stadtlazarethes am Olivaerthor zu Dank verpflichtet, der mir gleichzeitig die Benutzung seines Laboratoriums gestattete.

I. Paul M., aufgenommen am 12.VIII. 1896. Angeblich schon seit 14 Tagen krank. Bei der Aufnahme Roseolaexanthem an Gesicht, Brust, Bauch, Rücken. Am selben Tage werden zwei der Flecken incidirt und 3 Agar- und 2 Bouillonröhrehen daraus geimpft. Je 1 Agar- und Bouillonröhrchen bleiben steril, auf 2 Agarröhrchen wachsen einige Colonieen Staphyl. alb., sowie ein dicker, nach Gram gefärbter Bacillus, das 2. Bouillonröhrchen enthält Typhus in Reincultur. Bei zwei späteren Untersuchungen gelang es nicht mehr, aus den bereits im Abblassen begriffenen und spärlicheren Roseolen die Bouillon zn prüfen. - Klinisch deutlicher Fall. Widal erst am 22. VIII. positiv. 
II. Fritz N., 7 Jahre alt. Bei der Aufnahme am 26. VIII. 1897 Fieber über $39 \cdot 0^{\circ}$, Diazoreaction positiv, auf dem Rumpfe einige suspecte Flecke, die sich in den nächsten Tagen schnell vermehren. Kein Durchfall, keine Milzschwellung. Widal'sche Reaction negativ. Bei zweimaliger Untersuchung der Fäces werden keine Typhusbacillen gefunden. Am 27. VIII. zwei Roseolen untersucht. 2 Agar-, 1 Bouillonröhrchen steril, $2 \mathrm{Mal}$ in Bouillon nur dicke Kokken, 1 Mal Typhusbacillen gewachsen. Dieselben erschienen in dieser Cultur als fast unbeweglich und waren grössten Theils zu Haufen zusammengeballt. Agarplatten, daraus angelegt, ergaben Reincultur voll beweglicher Typhusbacillen. Am nächsten Tage wurde behufs genauer Titrirung der Agglutinationswirkung des Blutes ein Schröpfkopf an einer Stelle der Brust gesetzt, wo das Exanthem inzwischen so ausserordentlich reichlich entwickelt war, dass dabei mindestens 10 bis 15 Roseolen eröffnet sein mussten. Das so gewonnene Blut erwies sich jedoch als völlig steril; offenbar waren zahlreiche Typhuskeime darin abgetödtet. Erst am 11. IX. ergab die wiederholte Prüfung nach Widal ein positives Resultat. Zwei Tage nach dem ersten Befunde wurden wiederum 3 Roseolen incidirt und aus einer eine Reincultur in Bouillon gewonnen, die ebenfalls das Bild einer unvollständigen Häufchenbildung bot.

III. B., Laboratoriumsdiener. Aufnahme am 1. XII. 1896. Beginn 4 Tage vorher mit Schüttelfrost und Schwindel. Fieber während der ersten Woche zwischen $38 \cdot 1$ bis $39 \cdot 0^{\circ}$, Angina, leichte Obstipation. Milzanschwellung fehlte stets, Diazoreaction negativ. Bakteriologische Stuhluntersuchung negativ. Verdacht auf Sepsis. Widal negativ. Am 3. XII. einige suspecte, jedoch nicht charakteristische Flecke. Am 4. XII. 3 derselben incidirt. In 3 Bouillonröhrchen, sowie im Condenswasser eine Agarcultur. Typhusbacillen rein (3 andere Bouillonröhrchen enthalten weisse Staphylokokken). Ein hemmender Einfluss des Serums macht sich auch hier bemerkbar. Als nach 7 stündigem Stehen im Brütschranke Agarausstriche aus den Bouillonröhrchen angelegt wurden, blieb ein Ausstrich aus einem Röhrchen, in dem sich bis zum nächsten Morgen ebenfalls Typhusbacillen entwickelten, ganz steril, die Ausstriche aus den beiden anderen ergaben 3, bezw. 8 Colonieen Typhusbacillen. Es zeigte sich also in allen ein erheblich verzögertes Wachsthum. Widal erst am 15. XII. positiv, nachdem das Fieber schon seit dem 7. abgefallen; in der Reconvalescenz erfolgte dann, wie meistens, noch sehr erhebliche Zunahme der Agglutinationswirkung.

IV. Hedwig F., $3^{3} / 4$ Jahre alt, aufgenommen am 14. VII. 1897. Seit 5 Tagen besteht Fieber, seit 2 Tagen ein Roseolenexanthem, sehr reichliche Flecke. 3 davon untersucht, aus jedem eine Bouilloncultur von Typhusbacillen, ausserdem auf einem Agarröhrchen, welches mit dem in Condenswasser verdünnten Blute bespült war, eine Anzahl von Typhuscolonieen (ausserdem 2 Colonieen Staphylokokken). 3 weitere Bouillon- und 1 Agarröhrchen steril. Widal am 16. VII. negativ, 18. VII. negativ, 23. VII. positiv; weiterhin Anstieg: am 19. VIII. 1:500 positiv. Recht schwerer und protrahirter Fall, erst am 7. VII. fieberfrei.

V. Mathee, klinisch ausgesprochener Typhus. Zahlreiche Roseolen, bereits seit 4 bis 5 Tagen bestehend. Aus 3 Roseolen 3 Agar-, 6 Bouillonculturen angelegt. Typhusbacillen im Condenswasser eines Agar-, sowie in 2 Bouillonröhrehen, einmal daneben weisse Staphylokokken. Auf den anderen 
Röhrchen nur Kokken, sowie einmal ein plumper, träge beweglicher Bacillus. Die Culturen werden in diesem Falle nur durch die typische Agglutination bei Zusatz von 1:40 Typhusziegenserum, sowie durch Wachsthum auf Lackmusmolke (Titrirung der gebildeten Säure, Vergleich mit einer ControlTyphus- und Colicultur) identificirt.

VI. Müller, aufgenommen am 13. VII. 1897. Seit etwa 10 Tagen krank, klinisch gut charakterisirter, schwerer Typhusfall. Erst am 27. VIII. typische, sehr reichliche Roseolen. Die erste Untersuchung fiel negativ aus. Am 30. VIII. wiederum 5 Roseolen incidirt, aus jeder je 1 Bouillon- und 1 Agarcultur angelegt. Nur in dem durch Bouillonzusatz vermehrten Condenswasser eines Agarröhrchens Typhusbacillen rein; auf den übrigen meist Staphylokokken angegangen. Widal am 16. VIII. negativ, 20. VIII. und 27. VIII. gleichfalls; 1. IX. positiv. Bakteriologische Stuhluntersuchung am 20. VIII. negativ.

VII. M., aufgenommen am 21. VIII. 1897. Seit etwa 4 Tagen krank, mit Diarrhöen. Temperatur $39.8^{\circ}$, Puls dikrot, Diazoreaction negativ. Die Diagnose konnte hier bei der ersten Untersuchung des Serums erwiesen werden; noch in der Verdünnung 1:200 deutliche Agglutination, im späteren Verlaufe bei noch stärkerer Verdünnung. Am 27. VIII. reichliche Roseolaeruption; 3 Roseolen werden untersucht, und in einem Bouillonröhrchen Reincultur von Typhusbacillen gewonnen.

VIII. Br., aufgenommen am 30. VIII. 1897. Schwerer Typhus, seit etwa 14 Tagen bestehend; Diazoreaction positiv, Milz palpabel. Am 2. IX. ziemlich reichliche Roseolen. 4 derselben untersucht, aus zweien im Condenswasser von Agarröhrchen Typhusbacillen, einmal durch Staphylokökken verunreinigt. Widal bei den ersten beiden Untersuchungen negativ, bei der dritten am 5. IX, positiv. Am 6. IX. gelang es Hrn. Dr. Uhlenhuth, aus den Fäces auf gewöhnlichen Agarplatten Typhus zu züchten. Bei einer Virulenzprüfung dieser mir freundlichst überlassenen Cultur blieb ein Meerschweinchen, mit $1 / 5$ Oese intraperitoneal inficirt, am Leben, ein anderes ging nach Injection $1 / 2$ Oese innerhalb 24 Stunden ein; von meiner Roseolencultur tödtete dagegen noch $1 / 5$ Oese und erst $1 / 10$ nicht mehr. Eine noch genauere Dosirung habe ich nicht versucht, da schon hieraus horvorging, dass die Cultur aus der Roseole gegenüber der aus den Fäces jedenfalls nicht abgeschwächt war.

IX. Albert S., aufgenommen am 13. IX. 1897. Seit angeblich 5 Tagen krank; hohes Fieber um $40^{\circ}$, Durchfälle; Diazoreaction negativ; keine Milzschwellung. Am 16. IX. tritt ein wenig charakteristisches Exanthem auf; aus 3 von den Hautflecken wird je 1 Agar- und Bouillonröhrchen beschickt; in einem der letzteren Typhusbacillen rein. Am 16. IX. Widal . (1:20) negativ, 4 Tage später, am 20. IX., 1:70 positiv.

$X$. Henschel, aufgenommen am 27.X. 1897. Seit 8 Tagen bereits unwohl. Klinisch wohl charakterisirter Typhusfall, mittelschwer; bis zum 16. XI., also über 3 Wochen, zieht sich das Fieber hin. Während dieser Zeit wurde $4 \mathrm{Mal}$ eine genaue Untersuchung der Agglutinationswirkung des Blutes vorgenommen; dieselbe lag stets unter $1: 30$. Auch in der Reconvalescenz ist das Blut des Patienten oftmals untersucht worden (im Ganzen wenigstens $10 \mathrm{Mal}$ ); aber auch hier immer mit demselben negativen Resultat. Es giebt also Typhusfälle, in denen während der ganzen Dauer der Krankheit, und der Reconvalescenz die Widal'sche Reaction fehlt. Am 6. XI. 
traten 2 Roseolen am Bauche, 1 am Oberschenkel auf. Die beiden ersteren untersuchte ich, es gelang mir jedoch nicht, die Bacillen daraus zu züchten. Desgleichen war eine 2 malige Untersuchung der Fäces ohne Resultat. Dagegen ergab sich, als das Blut Anfangs Januar 1898 von Hrn. Dr. Takaki, der mir seine Versuche freundlichst zur Verfügung gestellt hat, auf seine immunisirende Fähigkeit gegenüber der intraperitonealen Typhusinfection von Meerschweinchen geprüft wurde, deutlich das Vorhandensein specifischer Antikörper: $0.05 \mathrm{cem}$ des Serums schützte gegen 1 Oese besonders hoch virulenter Typhuscultur, während $0.2^{\mathrm{cm}}$ eines normalen Controlserums ungenügend war.

Die im Vorstehenden geübte Methode zur Gewinnung der Typhusbacillen aus den Roseolen basirt auf der Berücksichtigung der stark baktericiden Wirkung des Blutserums und sucht diese störende Wirkung möglichst auszuschalten. Sie steht hierin in bewusstem Gegensatze zu einer Methode der bakteriologischen Blutuntersuchung, welche im Gegentheil den baktericiden Wirkungen des extravasculären Blutes freien Spielraum lässt, und dieselben für den Endzweck der Untersuchung ausnutzt. In dem einen Falle ist die keimtödtende Kraft des Blutes das störende Moment in der Entersuchung und der Hauptgrund der Misserfolge, im anderen ein Mittel zur Gewinnung eines einwandfreien Resultates. Dies letztere ist der Fall bei Untersuchungen des Blutes auf septicämische und pyämische Infectionen. Ich benutze die Gelegenheit, hier auf diesen fundamentalen Unterschied hinzuweisen; denn, wenn auch wenigstens ein Theil der Thatsachen, worauf derselbe beruht, bereits lange bekannt ist, ein anderer implicite in diesbezŭglichen Untersuchungen enthalten, so ist dennoch meines Wissens dieser Unterschied niemals ausdrücklich klargestellt und jedenfalls noch bei den neuesten und sorgfältigsten Arbeiten auf diesem Gebiete gänzlich unberücksichtigt geblieben. So z. B. in den sehr ausgedehnten Blutuntersuchungen, die wir $K u ̈ h n a u^{1}$ verdanken. Der Autor untersuchte nicht die Roseolen von Typhuskranken, sondern das aus der Armvene in grösseren Quantitäten, meist 10 oder $20^{\mathrm{ccm}}$, entnommene Blut auf Tuberkelbacillen; hierbei wurde das aus der Punctionsnadel ausfliessende Blut direct in ein mit $50 \mathrm{~cm}$ Bouillon gefülltes Erlenmeyerkölbchen geleitet und hiervon eine Reihe von Agarplatten, meist 20 oder 30, gegossen. Auf diesem Wege gelang es, unter 10 von 41 Fällen Typhusbacillen zu erhalten; in recht spärlicher Zahl allerdings, indem auf der Summe der Platten (bei den positiven Fällen waren es meist 30) nur 2 bis höchstens 5 Colonieen aufgingen, d. h. man musste bis zu 15 Agarplatten anlegen, um eine einzige Typhuscolonie zu erhalten. Ich selbst habe keine derartigen Blutunter-

1 Ueber die Resaltate und die Leistungsfähjgkeit der bakteriologischen Blutuntersuchung im Dienste der klinischen Diagnostik. Diese Zeitschrift. Bd. XXV. S. 492. 
suchungen unternommen; wenn man von den Umständlichkeiten des Verfahrens absieht, so lässt sich die Möglichkeit nicht in Abrede stellen, die Bacillen im circulirenden Blute nachzuweisen, da sie doch in den Kreislauf übergehen müssen, um in den Roseolen (und eventuell metastatischen Eiterungen) erscheinen zu können; ja man darf vielleicht annehmen, dass sie regelmässig in das Blut übergehen, hier jedoch meist zu Grunde gehen, bevor sie Metastasen bilden. Voraussetzung hierzu ist jedoch, dass die abtödtende Wirkung des Blutes durch sofortige Verdünnung paralysirt wird, wie es bei Kühnau's Untersuchongen geschah.

Nun wendet aber der Verfasser ganz dieselbe Methode bei Untersuchung einer Reihe von Fällen von Septicämie und Pyämie an. Die Hauptschwierigkeit sieht er dabei, wie die meisten seiner Vorgänger auf diesem Gebiete, in drohenden Verunreinigungen, besonders durch Hautsaprophyten. Trotz aller Cautelen liessen sich diese auch bei der Venenpunction nicht absolut vermeiden, und über ihre Bedeutung gaben auch Thierversuche nicht immer eine sichere Aufklärung, insofern, als der hauptsächlich in Betracht kommende Staphylococcus albus sich oft thierpathogen zeigt, auch wo er sicher als ein von der Haut in das Blut gelangter Saprophyt anzusehen war.

Die Blutentnahme durch sterile Schröpfköpfe nach Petruschky ${ }^{1}$ glaubt der Autor gar nicht empfehlen zu dürfen: ,auch bei diesem Verfahren werden ja eine grosse Reihe von Hautfollikeln eröffnet, die dem ausfliessenden Blute die in ihnen nistenden Keime beimischen, die sich nur in den Händen bewährtester bakteriologischer Forscher als solche erkennen lassen." Genau in demselben Sinne äussern sich andere Autoren, die auf diesem Gebiete gearbeitet haben. Da sie sich überzeugten, wie häufig man Hautkeime erhält, wenn man nach der alten Methode durch einen kleinen Hautschnitt, z. B. aus der Fingerkuppe, einige Blutstropfen entnimmt, so folgern sie daraus, dass entsprechend der grösseren Anzahl der Schnitte, die der Schröpfschnepper macht, auch die Gefahr wachse, Hautbakterien anstatt der gesuchten pathogenen zu züchten, und dass es einer ganz besonderen Uebung bedürfe, um hinterher beide aus einander zu halten.

Es genügt jedoch ein einziger praktischer Versuch, um das Unrichtige dieser Bedenken kennen zu lernen.

Bei der Methode von Petruschky besorgt nämlich die baktericide Kraft des Blutes die erwünschte Differenzirung viel zuverlässiger, als alle künstlichen Massnahmen, indem fremde Keime, etwa aus den Drüsenausführungsgāngen stammend, abgetōdtet werden, diejenigen Keime jedoch, welche im lebenden Blute circulirten und sich vermehrten, auch im extravàsculären Blute unbeeinflusst bleiben.

${ }^{\prime}$ Diese Zeitschrift. Bd. XVII. 
Dass die im Blute enthaltenen Keime in das sich allmählich abscheidende Serum übergehen und hier entwickelungsfähig bleiben, hat Petruschky in seiner Arbeit zur Genüge nachgewiesen; den Mangel fremder Keime führt er auf die Sterilisirung der Haut durch Alkohol und Aether zurück, indem er, wenn er von derartig gereinigten Hautflächen mit einem Scalpell oberflächlich Hautschuppen abkratzte, dieselben in der Regel steril fand. Zweifellos wird hierdurch also die Hauptmasse der Hautkeime vernichtet. Dennoch ist es mir gerade während meiner Roseolenuntersuchungen zweifelhaft geworden, ob sich diese Desinfectionswirkung auch bis in die Ausführungsgänge der Hautdrüsen erstreckt; denn, wie aus den angeführten Resultaten ersichtlich, habe ich dabei nach AlkoholAether-Reinigung sehr häufig Verunreinigungen der Culturen beobachtet, während mehrfach Schröpfköpfe, die bei denselben Fällen nach der gleichen Hautreinigung gesetzt wurden und eine Reihe ron Roseolen eröffneten, ein völlig steriles Blut enthielten. $\mathrm{Ja}$, ich habe Patienten ohne jede vorhergehende Reinigung der Haut schröpfen lassen, und auch so öfters keimfreies Blut erhalten. Allerdings war dies nicht immer der Fall; besonders bei schmutziger Haut sind wohl die Hautsaprophyten zum Theil in fettige Massen eingehüllt und so von der Abtödtung geschützt.

Ich habe des Weiteren direct Versuche über die Wirkung menschlichen Blutserums auf weisse Staphylokokken (von der Haut und aus der Mundhöhle stammend) angestellt und dabei eine erhebliche abtödtende Kraft gefunden.

Dagegen habe ich mehrere, aus pathologischen Processen vom Menschen stammende Streptokokkenstāmme, zwei Culturen von Staphylococcus aureus, aus einer puerperalen Sepsis und einer Pyämie gewonnen, sowie endlich einige Pneumokokkenculturen einer entsprechenden Untersuchung unterworfen und hierbei ein völlig entgegengesetztes Ergebniss erhalten: keines der untersuchten Menschensera vermochte auch die geringste Menge von Keimen der genannten Arten abzutödten oder auch nur in ihrer Entwickelung zu hemmen. Wenn ich auch nur wenige Keime in 0.2 bis $0.5^{\text {eern }}$ Serum einbrachte, so fand ich auch nach 24 Stunden und länger (bei $38^{\circ}$ gehalten) niemals eine Abtödtung, sondern stets eine Vermehrung derselben. -Weitere Untersuchungen müssen lehren, ob die genannten Mikroorganismen in der That durch ihr Verhalten dem menschlichen Blutserum gegenüber eine ganz exceptionelle Stellung einnehmen.

Nachtrag bei der Correctur. Nach Abschluss dieser Arbeit hatte ich Gelegenheit, weitere 4 Typhusfälle zu untersuchen, wobei es jedes Mal gelang, die Typhusbrcillen aus einer Roseole zu züchten. 